\title{
NERVE INJURY AFTER POSTERIOR AND DIRECT LATERAL APPROACHES FOR HIP REPLACEMENT
}

\author{
A CLINICAL AND ELECTROPHYSIOLOGICAL STUDY
}

\author{
ADRIAN E. WEALE, PIERS NEWMAN, \\ IAN T. FERGUSON, GORDON C. BANNISTER
}

From Southmead Hospital, Bristol, England

$\mathbf{N}$ erve injury is a rare complication of total hip replacement which may be related to the exposure used for the operation. The posterior approach is traditionally associated with injury to the sciatic nerve. We have compared the incidence of nerve injury after primary total hip replacement (THR) using either a posterior or a direct lateral approach.

We studied 42 consecutive patients undergoing primary total hip replacement. The surgeons used a posterior ( 22 patients) or direct lateral ( 20 patients) approach in accordance with their normal practice. The obturator, femoral, posterior tibial and common peroneal nerves were assessed clinically and electrophysiologically by electromyography (EMG) and measurement of the velocity of nerve conduction before operation and at four weeks after.

All patients were free from symptoms of nerve injury after operation but five lesions were identified in four patients by the electrophysiological studies; the obturator nerve was involved in two, the femoral in one, the common peroneal in one and the posterior tibial in one. All these injuries occurred using the lateral approach.

Clinical assessment alone underestimates the incidence of nerve injury complicating THR. Our study does not confirm the association of nerve injury with the posterior approach which had been described previously.

J Bone Joint Surg [Br] 1996;78-B:899-902.

Received 12 February 1996; Accepted after revision 26 June 1996

A. E. Weale, FRCS, Senior Orthopaedic Registrar

P. Newman, MRCP, Neurology Registrar

I. T. Ferguson, MD, FRCP, Consultant Neurologist

G. C. Bannister, MD, MCh Orth, FRCS, Consultant Orthopaedic Surgeon

Avon Orthopaedic Centre, Southmead Hospital, Westbury-on-Trym, Bristol BS10 5NB, UK

Correspondence should be sent to $\mathrm{Mr} \mathrm{A}$. E. Weale at the Department of Orthopaedic Surgery, Bristol Royal Infirmary, Marlborough Street, Bristol BS2 8HW, UK.

(C)1996 British Editorial Society of Bone and Joint Surgery 0301-620X/96/66603\$2.00

Nerve palsy is a rare complication of total hip replacement (THR) and recovery is often incomplete. The clinical incidence is between $0.3 \%$ (Johanson et al 1983) and 4\% (Wilson and Scales 1973) in primary procedures, but electromyographic (EMG) studies indicate that nerve injury may occur in up to $70 \%$ of cases (Weber, Daube and Coventry 1976). Revision arthroplasty, lengthening of the leg by more than $4 \mathrm{~cm}$ (Edwards, Tullos and Noble 1987), congenital dislocation (Schmalzreid, Amstutz and Dorey 1991), haemorrhage, the duration of the operation (Johanson et al 1983), and intrapelvic extrusion of cement (Siliski and Scott 1985) have all been implicated, but the cause of the injury is uncertain in most cases.

The published figures are derived largely from major centres using either the Charnley (1979) transtrochanteric or the posterior approaches (Table I) which are thus disproportionately represented. Muller (1970), Ratliff (1984) and Eftekhar (1993) all associated nerve palsy with the posterior approach. Since primary THRs are now most commonly performed without detachment of the trochanter, we wished to compare the incidence of nerve injury after the use of the posterior or the direct lateral approach.

\section{PATIENTS AND METHODS}

We performed electrophysiological examination before and after operation in 42 patients undergoing primary THR. All had given their consent and the study had been approved by the Ethical Committee.

No patient had diagnosed or suspected neurological disease or a history of sciatica with neurological signs. The diagnosis, age, gender and weight of the patient were recorded (Table II).

The posterior gluteal splitting approach (Moore 1957) was used in 22 patients and the direct lateral transgluteal approach (Hardinge 1982) in 20, according to the usual practice of the surgeon.

Posterior approach. The patients were positioned in the lateral position. The gluteus maximus was split along the line of its fibres. The conjoined tendons of the external rotators were transfixed with a stay suture and after division at their femoral insertion were retracted to protect the sciatic nerve. The hip was dislocated posteriorly by internal rotation, flexion and adduction. 
Table I. The incidence of nerve injury complicating total hip replacement in clinical studies using the transtrochanteric and posterior approaches

\begin{tabular}{llrrr}
\hline Year & Author & $\begin{array}{l}\text { Number } \\
\text { of patients }\end{array}$ & Incidence & Percentage \\
\hline Transtrochanteric & Charnley and Cupic & 185 & 2 & 1.0 \\
1973 & Wilson and Scales & 108 & 4 & 4.0 \\
1973 & Weber et al & 2012 & 17 & 0.8 \\
1976 & Eftekhar, Kiernan and Stinchfield & 800 & 12 & 1.5 \\
1976 & Robinson, Robinson and Salvati & 156 & 2 & 1.3 \\
1980 & Jinnah et al & 149 & 6 & 4.0 \\
1986 & Navarro et al & 460 & 5 & 1.0 \\
1995 & & 3870 & 48 & 1.2 \\
Total & & & & \\
& & & & \\
Posterior & Smith & 112 & 1 & 0.9 \\
1973 & Murray & 557 & 10 & 1.8 \\
1973 & Sarmiento et al & 237 & 7 & 2.9 \\
1979 & Robinson et al & 160 & 0 & 0.0 \\
1980 & Tillberg & 327 & 3 & 0.9 \\
1982 & Ahlgren et al & 150 & 1 & 0.7 \\
1984 & Andrew et al & 179 & 1 & 0.6 \\
1985 & Søballe et al & 141 & 1 & 0.7 \\
1987 & Mok and Bryant & 251 & 4 & 1.6 \\
1989 & Navarro et al & 540 & 3 & 0.6 \\
1995 & & 2654 & 31 & 1.2 \\
Total & & &
\end{tabular}

Table II. Details of patients and operations

\begin{tabular}{lccl}
\hline & Lateral approach & Posterior approach & $\begin{array}{l}\text { p value } \\
\text { of differences }\end{array}$ \\
\hline Mean age in years & 68.5 & 69.4 & NS \\
Mean weight in kg & 74.2 & 71.3 & NS \\
Male:female & $11: 9$ & $7: 15$ & NS \\
Grade of operating surgeon & & & \\
$\quad$ Consultant & 7 & 12 & NS \\
$\quad$ Trainee & 13 & 10 & \\
Mean blood loss in ml & 768 & 599 & $<0.001$ \\
Mean operating time in min & 107 & 78 & $<0.05$
\end{tabular}

Direct lateral approach. The patient lay supine. The gluteal fascia and iliotibial band were exposed and divided along the midlateral line. The glutei were split obliquely across the greater trochanter leaving the posterior two-thirds still attached. The incision was carried distally in line with the fibres of vastus lateralis. The tendinous insertions of the glutei and the vastus lateralis were elevated, exposing the anterior capsule. The hip was dislocated anteriorly by external rotation and adduction.

Of the 42 operations, 19 were performed by consultants and 23 by either trainees or staff grade surgeons. There was no significant difference in the proportion of operations done by the grade of surgeon in either the posterior or the direct lateral groups. Intraoperative blood loss, the length of the procedure, radiological evidence of leg lengthening and intrapelvic extrusion of cement were recorded. The function of the femoral, obturator, common peroneal and posterior tibial divisions of the sciatic nerve were assessed clinically by the second author (PN) and electrophysiologically before operation and four to five weeks after.

Clinical assessment. Motor power was graded in accord- ance with the MRC scale (Medical Research Council Memorandum No: 45 1976). The flexors and extensors of the hip, knee, ankle and toe were specifically tested, as were adduction of the hip and inversion and eversion of the ankle. Abnormalities of sensation over the distribution of the saphenous, common peroneal and posterior tibial nerves were recorded. The knee and ankle reflexes were elicited.

Electrophysiological assessment. All patients had EMG by multiple concentric needle puncture of the medial head of gastrocnemius (posterior tibial nerve), the tibialis anterior and the long head of biceps femoris (common peroneal nerve), the vastus lateralis (femoral nerve) and the gracilis (obturator nerve). The diagnosis of denervation was made by the detection of fibrillation potentials in three areas of muscle at least $1 \mathrm{~cm}$ apart.

The velocity of motor nerve conduction and the amplitude of the compound action potential were measured in the common peroneal nerve, proximal and distal to the head of the fibula, and in the posterior tibial nerve in the lower leg using surface electrodes. Nerves were stimulated supramaximally at multiple sites along the course of the nerve 
and motor responses were recorded from the extensor digitorum brevis and the abductor hallucis. The conduction velocity was determined by measuring the distance between the site of stimulation and the site of recording and dividing this by the latency of response.

Statistical methods. Categorical data were analysed by the two-tailed Fisher exact test and continuous data by the Student's $t$-test or the Mann Whitney U test.

\section{RESULTS}

Clinical. The mean blood loss and operating time were less with the posterior approach (Table II). Four of the 22 hips replaced by this exposure showed leg lengthening of $1 \mathrm{~cm}$ or less, compared with 6 of the 20 using the direct lateral approach. Intrapelvic extrusion of cement was not seen.

There were no clinical symptoms or signs of motor or sensory nerve deficit in either group before or after the operation.

Electrophysiological tests. No nerve lesions were identified before operation. After THR, five nerve injuries were identified in four patients. There were two injuries to the obturator nerve, one to the femoral, one to the posterior tibial and one to the common peroneal nerves. One patient had injuries to both the obturator and femoral nerves. All the injuries to nerves occurred in patients whose hips had been replaced through a direct lateral approach. Nerve injury was not associated with the grade of the surgeon or the age or weight of the patient.

\section{DISCUSSION}

Our study confirms the observation of Weber et al (1976) that clinical examination alone underestimates nerve injury after THR. No injury was seen with the posterior approach but $20 \%$ of patients whose hips had been replaced by the direct lateral approach, showed some evidence of nerve injury. Weber et al (1976) found an incidence of $70 \%$ in hips replaced through the transtrochanteric approach and Ahlgren, Elmqvist and Ljung (1984) noted abnormality after $8 \%$ of operations performed through the posterior approach. The declining incidence with time probably represents the influence of increasing expertise in total hip replacement.

The significance of the reported prevalence of nerve injury is masked, since only severe damage presents as a clinical complication. Nerve injury can vary from transient blocks in conduction to irreversible damage secondary to the mechanical disruption of axons within the endoneural sheath (Wasielewski, Crossett and Rubash 1992). The criterion used to diagnose nerve injury in our study was the occurrence of fibrillation potentials on EMG: this is absolute proof of discontinuity of the axons (Sunderland 1991).

The exposure gained by the Charnley transtrochanteric approach involves the use of sturdy self-retaining retractors with which it is possible to exert considerable traction on the soft tissues. Such retractors were used in our series by surgeons approaching the hip through the direct lateral approach, and this, together with retractor placement anteriorly and inferiorly, was probably responsible for the injuries to the femoral and obturator nerves. The posterior route is more anatomical than the direct lateral; less traction is required to gain sufficient access to perform total hip arthroplasty, the operating time is shorter and the blood loss less. We have therefore not been able to confirm the association of nerve injury with the posterior approach which was identified by previous authors.

The authors wish to acknowledge the assistance of Dr D. Prothero, PhD with the analysis of the results and Mr R. Birch, MChir, FRCS for his helpful comments on the manuscript.

No benefits in any form have been received or will be received from a commercial party related directly or indirectly to the subject of this article.

\section{REFERENCES}

Ahlgren SA, Elmqvist D, Ljung P. Nerve lesions after total hip replacement. Acta Orthop Scand 1984;55:152-5.

Andrew TA, Berridge D, Thomas A, Duke RNF. Long-term review of Ring total hip arthroplasty. Clin Orthop 1985;201:111-22.

Charnley J. Low friction arthroplasty of the hip: theory and practice. Berlin, etc: Springer-Verlag, 1979:20-5.

Charnley J, Cupic Z. The nine and ten year results of the low-friction arthroplasty of the hip. Clin Orthop 1973;95:9-25.

Edwards BN, Tullos HS, Noble PC. Contributory factors and etiology of sciatic nerve palsy in total hip arthroplasty. Clin Orthop 1987;218:136-41.

Eftekhar NS. Applied surgical approaches. In: Eftekhar NS, ed. Total hip arthroplasty. Mosby, 1993:51-74.

Eftekhar NS, Kiernan HA, Stinchfield FE. Systemic and local complications following low-friction arthroplasty of the hip joint: a study of 800 consecutive operations. Arch Surg 1976;111:150-5.

Hardinge K. The direct lateral approach to the hip. J Bone Joint Surg [Br] 1982;64-B:17-9.

Jinnah RH, Amstutz HC, Tooke SM, Dorey F, Dalseth T. The UCLA Charnley experience: a long-term follow-up study using survival analysis. Clin Orthop 1986;211:164-72.

Johanson NA, Pellicci PM, Tsairis P, Salvati EA. Nerve injury in total hip arthroplasty. Clin Orthop 1983;179:214-22.

Medical Research Council. Aids to the examination of the peripheral nervous system. London: HMSO, 1976.

Mok DWH, Bryant KM. Ring uncemented plastic-on-metal hip replacements: results from an independent unit. $J \quad R$ Soc Med 1989;82:142-4.

Moore AT. The self-locking metal hip prosthesis. J Bone Joint Surg [Am] 1957;39-A:811-27.

Muller ME. Total hip prostheses. Clin Orthop 1970;72:46-68.

Murray WR. Results in patients with total hip replacement arthroplasty. Clin Orthop 1973;95:80-90.

Navarro RA, Schmalzried TP, Amstutz HC, Dorey FJ. Surgical approach and nerve palsy in total hip arthroplasty. J Arthroplasty 1995;10:1-5.

Ratliff AHC. Vascular and neurological complications. In: Ling RSM, ed. Complications of total hip replacement. (Current problems in orthopaedics). Edinburgh, etc: Churchill Livingstone, 1984:18-29.

Robinson RP, Robinson HJ Jr, Salvati EA. Comparison of the transtrochanteric and posterior approaches for total hip replacement. Clin Orthop 1980;147:143-7.

Sarmiento A, Zych GA, Latta LL, Tarr RR. Clinical experiences with a titanium alloy total hip prosthesis: a posterior approach. Clin Orthop 1979;144:166-73.

Schmalzreid TP, Amstutz HC, Dorey RJ. Nerve palsy associated with total hip replacement. J Bone Joint Surg [Am] 1991;73-A:1074-80. 
Siliski JM, Scott RD. Obturator nerve palsy resulting from intrapelvic extrusion of cement during total hip replacement: report of four cases. J Bone Joint Surg [Am] 1985;67-A:1225-8.

Smith RD. Total hip replacement: metal against metal: review and analysis of cases 1961-1972. Clin Orthop 1973;95:43-7.

Søballe K, Olsen NJ, Ejsted R, Christensen F, Luxhøj T. Revision of the uncemented hip prosthesis. Acta Orthop Scand 1987;58:630-3.

Sunderland S. Nerve injuries and their repair: a critical appraisal. Churchill Livingstone, 1991.
Tillberg B. Total hip arthroplasty using the McKee and Watson-Farrar prosthesis: a prospective follow-up study of 327 arthroplasties. Acta Orthop Scand 1982;53:103-7.

Wasielewski RC, Crossett LS, Rubash HE. Neural and vascular injury in total hip arthroplasty. Orthop Clin North Am 1992;23:219-35.

Weber ER, Daube JR, Coventry MB. Peripheral neuropathies associated with total hip arthroplasty. J Bone Joint Surg [Am] 1976;58-A:66-9.

Wilson JN, Scales JT. The Stanmore metal on metal total hip prosthesis using a three pin type cup: a follow-up of 100 arthroplasties over nine years. Clin Orthop 1973;95:239-49. 